\title{
Serotonin: Beyond the Brain
}

\author{
Paul M. Vanhoutte \\ Department of Pharmacology and Pharmacy, The University of Hong Kong, Hong Kong, China
}

ABSTRACT: The Serotonin Club has played a crucial role in disseminating information on the roles played by this monoamine neurotransmitter, as well as in the process of pharmacological classification of serotonin membrane receptors. The Club's future mission should be to emphasize that serotonin (5-hydroxytyptamine) contributes to physiology and pathology beyond its function in the central nervous system.

KEYWORDS: Serotonin Club, serotonin, 5-hydroxytyptamine

W hen with a group of devoted "serotoninologists" (Efrain Azmitia, Marlene Cohen, Ian de la Lande, John Fozard, Richard Green, Ray Fuller, Patrick Humphrey, David Nelson, Elaine Sanders-Bush, Pramod Saxena, Noboru Toda, and Jan Van Nueten) started the Serotonin Club in Sydney, we certainly did not envisage that a quarter of a century later the Club would still be going strong, as is evident from the recent meeting in Montpellier. Of course, in 1987, most of us were too eager regarding the issues of the day to think 25 years hence; creating this soon-to-be successful venture was more a sign of naivety than of foresight. Little did we know that the Serotonin Club would have a major impact on Pharmacology overall. Indeed, the primary task of early Club members was to try to bring order and method to the way serotonin receptors were classified and named. As discussed elsewhere, ${ }^{1}$ I lost the battle between nomenclature involving " $\mathrm{S}$ " vs " 5 -HT" to classify the 16 serotonin receptors that are currently identified. However, I won the war surrounding the use of "serotonergic" versus "5hydroxytryptaminergic" (I still cannot pronounce the latter!) to describe serotonin receptors. When I took over the International Union of Basic and Clinical Pharmacology Nomenclature Committee (NC-IUPHAR) in 1989, those early efforts of the Serotonin Club turned out to be an invaluable experience that enabled me to put this IUPHAR Committee on the right track and to become NC-IUPHAR, a major player in the discipline of Pharmacology. That contribution per se justifies the existence of the Serotonin Club. But of course, over the years, the Club's meetings have been more than that, as they are the venue of choice to divulge novel findings, in particular, as regards the role of 5-hydroxytryptamine as an essential signaling molecule.

Irvine Page, in a lovely essay written in 1985, paraphrased one of his earlier statements that, for him, serotonin had been rather of a nuisance making the study of angiotensin more complicated. ${ }^{2}$ As pointed out by Dr. Page, the discovery of serotonin in brain, where it promptly became known as 5hydroxytryptamine, forever diverted the serotonergic spotlight from the circulatory system to the central nervous system. This is quite obvious for those who attended the meeting in Montpellier or read this special issue of ACS Chemical Neuroscience. In the early 1980s, I entered the serotonin arena through its original entry door when I became passionately interested in the potential of circulating platelets to deliver both vasodilator and vasoconstrictor signals to the vasculature walls.

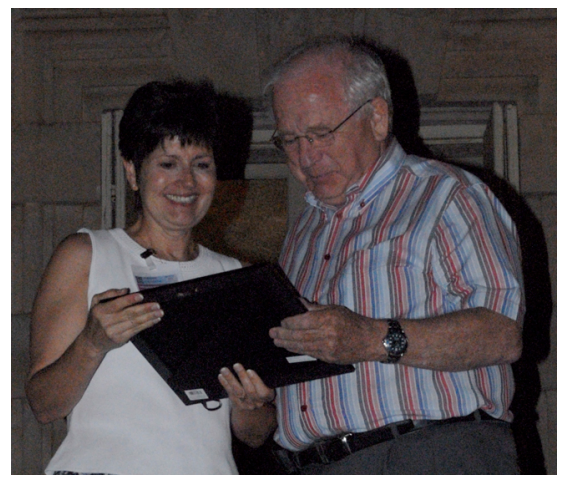

Figure 1. Receiving an award from Julie Hensler. Image courtesy of Joël Bockaert.

I soon became, and remain, convinced that platelet-derived serotonin, by its dual action on endothelial and vascular smooth muscle cells, is a fundamentally important signaling molecule that prevents unwanted coagulation of blood in healthy blood vessels, while accelerating coagulation when vessel integrity is endangered. ${ }^{3}$ Serotonin was discovered early in the blood, with relatively primitive techniques, as is the case for the other primordial cardiovascular mediators, the catecholamines, that is, ephinephrine and norepinephrine, and angiotensin II. This is no coincidence, but it illustrates the essential regulatory role that these substances play. Fashions in science being what they are, in 2012, very few cardiovascular scientists pay attention to the ability of aggregating platelets to release this vasoactive modulator. Hence, it is encouraging to see that at least a handful of investigators remain convinced of the importance of serotonin in cardiovascular health and disease, ${ }^{4,5}$ and the functions that serotonin serves beyond its role in brain. Given the critical roles of serotonin in both the brain and the periphery, the major mission of the Serotonin Club should be to bring the message to the scientific community that 5hydroxytryptamine is more than a central nervous system

Special Issue: Celebrating 25 Years of the Serotonin Club

Received: December 11, 2012

Accepted: December 13, 2012

Published: January 16, 2013 
neurotransmitter as it importantly contributes to the regulation of other organs!

Dr. Page wrote a few years before the start of the Serotonin Club: "Serotonin has taken a life of its own and we are no longer living together. I have no regrets, because a long life has taught me that the natural history of one's active participation in a discovery is about 5 to 10 years. Then the subject grows complicated, new very bright young faces appear with their better methods and they take over. If they are aware that anything preceded their own work, they give no indication of it, which is nature's way of preventing constipation of the mind." I may not agree with the first sentence, as after 30 years serotonin is still as fascinating to me as ever. Those of us who were fortunate to attend the meeting in Montpellier can only agree with the second of Dr. Page's sentiments, as the quality of the presentations by the young investigators was overwhelming. As to his third statement and the eternal danger of rediscovering the wheel, the reader can decide for him/herself.

\section{AUTHOR INFORMATION}

Notes

The authors declare no competing financial interest.

\section{REFERENCES}

(1) Vanhoutte, P. M. (2009) My twenty years at IUPHAR. Pharmacol. Int., 26-29.

(2) Page, I. H. (1985). The neonatology of Serotonin. In Serotonin and the Cardiovascular System (Vanhoutte, P. M., Ed.), pp xiii-xv, Raven Press, New York.

(3) Vanhoutte, P. M., Tang, E., Félétou, M., and Shimokawa, H. (2009) Endothelial dysfunction and vascular disease. Acta Physiol. 196, 193-222.

(4) MacLean, M. R, and Dempsie, Y. (2009) Serotonin and pulmonary hypertension: From bench to bedside? Curr. Opin. Pharmacol. 9, 281-286.

(5) Watts, S. W., Morrison, S. F., Davis, R. P., and Barman, S. M. (2012) Serotonin and blood pressure regulation. Pharmacol. Rev. 64, 359-388. 